\title{
How Big are Potential Welfare Gains from International Risksharing? ${ }^{1}$
}

\author{
Eric van Wincoop \\ Federal Reserve Bank of New York
}

August 25, 1998

\footnotetext{
${ }^{1}$ Eric van Wincoop, International Research Function, Federal Reserve Bank of New York, 33 Liberty St., New York, NY 10045. phone: 212-720-5497, fax 212-720-6831, e-mail eric.vanwincoop@ny.frb.org.
} 


\begin{abstract}
There is extensive evidence that risksharing across countries is far from perfect. Some have attributed this to small benefits from risksharing. Gains from riskpooling that have been reported range from negligible to enormous. This paper documents to what extent the results are sensitive to the parameterization of preferences, the stochastic process of the endowment, and its measurement. We find that gains from risksharing are quite sizable for realistic assumptions about the underlying factors. For OECD countries they are equivalent to an increase in tradables consumption in the range of 1.1 to $3.5 \%$ for a 50 year horizon, and 2.5 to $7.4 \%$ for a 100 year horizon.
\end{abstract}

JEL F30, F41, G15; keywords: international risksharing, welfare gains 


\section{Introduction}

Are we close to fully exploiting the potential benefits from international asset markets? This is currently a hotly debated question in light of the process of financial integration and globalization in the past few decades. Three types of evidence suggest that risksharing across countries is still far from perfect. First, as documented by French and Poterba (1991) and Tesar and Werner (1994), the percentages of aggregate stock-market wealth invested in domestic equities at the beginning of the 1990 s were well above $90 \%$ for the US and Japan, and around $80 \%$ in the UK and Germany. Second, trade in claims on a broad measure of national outputs is currently non-existent. Shiller (1993) has made a strong case for the introduction of such "macro markets". Third, Backus, Kehoe and Kydland (1992) find that the low cross country consumption correlations are inconsistent with real business cycle models that assume perfect risksharing.

All of this is not necessarily surprising if the potential welfare gains from risksharing are small, so that small transaction costs can account for the lack of observed risksharing. There are at least fourteen papers in recent years that have computed welfare gains from international risksharing. ${ }^{1}$ The gains are usually reported as the permanent percentage increase in expected consumption that leads to an equivalent increase in welfare. The reported results vary enormously, ranging from less than $0.1 \%$ to over $100 \%$. This has led to significant confusion about the true magnitude of the gains from international risksharing.

This paper has two goals. The first is to document the extent to which the results are sensitive to assumptions about the consumption measure, the horizon, the type of 'autarky' consumption process, the implicit risk-free interest rate, the rate of relative risk-aversion, and the elasticity of substitution between traded and non-traded goods. The second is to narrow down the welfare gain estimates by using as much information as possible on these various factors. This leads to an estimate of the range within which the potential welfare gains are likely to fall. The main finding of the paper is that potential welfare gains from risksharing among OECD countries are large: 1.1 to $3.5 \%$ for a 50 year horizon, and 2.5 to $7.5 \%$ for a 100 year horizon.

The remainder of the paper is organized as follows. Section 2 briefly reviews the existing literature and explains why some authors have found extraordinary low welfare gains. Section 3 reports potential gains from risksharing when preferences are additively separable in traded and non-traded goods, paying careful attention to the various factors

\footnotetext{
${ }^{1}$ Backus, Kehoe and Kydland (1992), Brennan and Solnik (1989), Cole and Obstfeld (1991), Devereux and Lee (1997), Kose (1995), Lewis (1996a), Mendoza (1995), Obstfeld (1994a,b,1995), Shiller and Athanasoulis (1995), Tesar (1995), and van Wincoop (1994,1996).
} 
listed above. Section 4 considers the role of non-separability between traded and nontraded goods, assuming CES preferences. The final section summarizes the main results and suggests directions for future research.

\section{The Welfare Gain Literature in Perspective}

Papers that have reported very small gains from international risksharing (less than 0.5\%) are Backus, Kehoe and Kydland (1992), Cole and Obstfeld (1991), Mendoza (1995), Obstfeld (1994b), and Tesar (1995). Others, such as van Wincoop (1994,1996), Lewis (1996a), Shiller and Athanasoulis (1995), Obstfeld (1994a,1995), and Kose (1995), report much larger welfare gains.

As shown in van Wincoop (1994) in the context of an infinite horizon endowment economy, the welfare gain from international risksharing depends on four factors: (i) the implicit risk-free interest rate, (ii) the risk-adjusted growth rate, (iii) the rate of relative risk-aversion, and (iv) endowment uncertainty. The welfare gain expression is the same for time-separable expected utility preferences, non-expected utility preferences and habit formation preferences. ${ }^{2}$ It is useful to use the factors (i)-(iv) as a guide in comparing the results of the various papers.

In several of the papers reporting low welfare gains, this is to a great extent the result of a parameterization whereby the implicit riskfree rate is excessively high: $5.6 \%$ to $56 \%$ in Cole and Obstfeld (1991) and 7\% to 45\% in Obstfeld (1994b). We illustrate in section 3.2 that such high interest rates can indeed significantly reduce the welfare gain measure. Lewis (1996a) reports welfare gains from risksharing among the G-7 countries when the parameterization is such that the riskfree rate in the data is matched. The average reported welfare gain is $32 \%$. This is so high because the equity premium is matched as well. This requires a rate of relative risk-aversion well above 50, which is significantly above consensus estimates and is known as the equity premium puzzle. As long as the equity premium puzzle remains unresolved, it is a potential source of uncertainty as to the precise magnitude of potential welfare gains. While this paper does not resolve that issue, and we do not attempt to match the equity premium, it is important to observe that there is not necessarily a direct relationship between the equity premium and welfare gains. Given (i)-(iv), as mentioned above, the welfare gain is the same for habit formation preferences as for the standard time-separable preferences, although the equity premium is known to be larger under habit formation.

To a great extent, differences in reported welfare gains are a result of different as-

\footnotetext{
${ }^{2}$ Non-separability between traded and non-traded goods is not considered in that paper.
} 
sumptions about endowment uncertainty. Sometimes low reported welfare gains are due to assumed stationary processes: Obstfeld (1994b) ${ }^{3}$, Tesar (1995) ${ }^{4}$, and Mendoza (1995). ${ }^{5}$ These results are best interpreted as showing small benefits from sharing aggregate business cycle risk among countries. This is consistent with Lucas (1987), who reports negligible gains from eliminating all business cycle risk. Under stationary processes, long term growth uncertainty is generally very small. At the other extreme, Shiller and Athanasoulis (1995) report a welfare gain of $29 \%$, but probably overstate long term growth uncertainty. They do not make assumptions about the underlying process for output, but compute a 12-country covariance matrix of output at various horizons under the assumption that all countries' expected growth rates are identical. This implies that differences in growth rates across countries are entirely unpredictable. ${ }^{6}$

In some papers the correlation of consumption across countries is very high even in autarky, resulting in low potential gains from risksharing. One example is Cole and Obstfeld (1991), where endogenous terms of trade fluctuations pool some of the risk associated with endowment shocks. This generally leads to much higher cross country consumption correlations than observed in the data. Another example is Backus, Kehoe and Kydland (1992), where international technology spillovers lead to a high cross country consumption correlation in autarky. This leads to a low welfare gain of $0.3 \%$ in the context of a two country real business cycle model. ${ }^{7}$

\footnotetext{
${ }^{3}$ Obstfeld (1994b) considers the gain from eliminating all risk for both stationary and non-stationary processes: the Lucas (1987) trend-stationary process where shocks are purely transitory, an $\operatorname{AR}(2)$ process in levels, a random walk process, and an AR process in growth rates. But even for the nonstationary processes the gains are generally still low due to the high riskfree rates.

${ }^{4}$ The welfare gains reported in Tesar (1995) are based on an AR process in the log of output, with AR coefficients of 0.9 and 0.995 . The reported gains are very low, e.g. $0.033 \%$ for a 'large' country when the rate of relative risk aversion is 5 and the AR coefficient is 0.995 . While this is close to a random walk, the standard deviation of the innovation is kept very low to make the unconditional variance of output $2.94 \%$ for a 'large' country, independent of the AR coefficient (this unconditional standard deviation is infinite for a pure random walk). Similar standard deviations are obtained when extracting a HodrickPrescott (100) filter from annual GDP data, which leaves only shocks at the business cycle frequency. This means that the results in Tesar (1995) should be interpreted as the gains from sharing risk associated with temporary business cycle shocks. I would like to thank Linda Tesar for clarifying this to me in several helpful discussions about this issue.

${ }^{5}$ Mendoza (1995) allows for stationary terms of trade and technology shocks in the context of a small open economy real business cycle model. For both shocks the assumed autocorrelation is 0.473.

${ }^{6}$ The $29 \%$ gain is based on trade of only two "optimal" assets among twelve countries. Another reason their welfare gains are high is because of some developing countries included in the sample. Obstfeld (1995) and Kose (1995) also report large welfare gains of risksharing among developing countries, although much lower than Athanasoulis and Shiller (1995).

${ }^{7}$ Their low reported welfare gain may also be based on approximations of decision variables as a linear function of state variables. In order to see that this can lead to deceiving results, consider the example of
} 


\section{Welfare Gain From Risksharing under Additively Sepa- rable Preferences}

This section computes the welfare gain from international risksharing when preferences are additively separable in tradables and non-tradables. Current consumption streams are considered to be endowments generated by an assumed process. We compute the welfare gain associated with trade in claims on these consumption endowment streams.

Let us say there are $J$ countries of equal size. It is assumed that residents from all countries are ex-ante identical: they have the same preferences and their consumption endowment streams are generated by the same process. If the stochastic properties of the endowments were different across countries, claims on these endowments would have to be priced in order to compute the welfare gains, as in van Wincoop (1994). Here we sidestep the pricing problem by assuming the same endowment process for all countries and using the unweighted average across countries of the estimated standard deviations of the innovations. The welfare gain should then be interpreted as corresponding to a "representative" country.

\subsection{Benchmark Model}

First consider a benchmark setup, where the endowment follows a random walk with drift. Expected utility is:

$$
V=E \int_{0}^{H} e^{-\beta t} \frac{\left(c_{i t}^{T}\right)^{1-\gamma}}{1-\gamma} d t
$$

Here $H$ is the horizon, $\gamma$ the rate of relative risk-aversion, and $c_{i t}^{T}$ consumption of tradables by residents of country $i$. Since utility is additively separable in tradables and non-tradables, and risksharing with respect to non-tradables is not possible, utility from non-tradables is omitted from (1).

The tradables consumption endowment is denoted $y_{i t}^{T}$, which follows a random walk with drift:

$$
d y_{i t}^{T}=\mu y_{i t}^{T} d t+\sigma_{T} y_{i t}^{T} d z_{i},
$$

where $z_{i}$ is a standard Brownian motion, and $\omega_{T}=d z_{i} d z_{j}(i \neq j)$ is the correlation of tradables endowment growth innovations across two different countries. In the absence

a one period two country model, with utility $E\left(\ln c_{i}+\ln L_{i}\right)$ in country $i$, where $L$ is leisure and output in country $i$ is $\theta_{i}\left(2-L_{i}\right)$. Under autarky $L=1$ and $c_{i}=\theta_{i}$. Under perfect risksharing the approximated linear decision rules (around $\theta_{i}=1$ ) are $c_{i}=0.5 \theta_{1}+0.5 \theta_{2}$ and $L_{1}=1-0.5 \theta_{1}+0.5 \theta_{2}$. Assume that the states of the world are $\left(\theta_{1}, \theta_{2}\right)=(0.5,2),(2,0.5)$, and $(0.75,0.75)$. The first two states have probability 0.25 , and the third state has probability 0.5. So $E \theta_{i}=1$. Expected utility under autarky and perfect risksharing are respectively -0.144 and -0.239 . 
of risksharing $c_{i t}^{T}=y_{i t}^{T}$, and the resulting expected utility is:

$$
V=\frac{\left(y_{i 0}^{T}\right)^{1-\gamma}}{1-\gamma} \frac{1-e^{-\psi T}}{\psi}
$$

where $\psi=\beta+(\gamma-1)\left(\mu-0.5 \gamma \sigma_{T}^{2}\right)$.

When agents engage in risksharing, tradables consumption in each country is equal to the per capita world endowment $y^{T W}: c_{i t}^{T}=y_{t}^{T W}=\sum_{j=1}^{J} y_{j t}^{T} / J$. This follows approximately a random walk with variance $\sigma_{T W}^{2}=\sigma_{T}^{2}\left(\frac{1}{J}+\left(1-\frac{1}{J}\right) \omega_{T}\right) .{ }^{8}$ Expected utility after risksharing is the same as (1), with $\sigma_{T W}$ replacing $\sigma_{T}$. The welfare gain is measured as the permanent percentage increase in the expected level of tradables consumption that yields an equivalent improvement in welfare. We find

$$
\text { gain } \approx-\left(1-H(r-\bar{\mu}) \frac{e^{-(r-\bar{\mu}) H}}{1-e^{-(r-\bar{\mu}) H}}\right) \frac{0.5 \gamma d \sigma_{T}^{2}}{r-\bar{\mu}}
$$

where $d \sigma_{T}^{2}=\sigma_{T W}^{2}-\sigma_{T}^{2}$ is the change in the variance of consumption growth, $\bar{\mu}=$ $\mu-0.5 \gamma \sigma_{T}^{2}$ is the risk-adjusted growth rate, and $r=\beta+\gamma \bar{\mu}$ is the (implicit) risk-free interest rate. The appropriate time discount rate is $r-\bar{\mu}$. It is useful to write the welfare gain as a function of the interest rate, which can be measured more easily than the underlying preference parameters.

A couple of results can be immediately derived from (4). First, the welfare gain is larger the longer the time horizon. The gain drops to zero when the horizon is infinitesimal. Second, when $r<\bar{\mu}$, the welfare gain approaches infinity when $H \rightarrow \infty$. The assumption that $r<\bar{\mu}$ appears consistent with the data. Mehra and Prescott (1985), using US data from 1889 to 1978, find an average real return on "relatively riskless, short-term securities" of $0.8 \%$ and a $1.8 \%$ average growth rate of per capita consumption. ${ }^{9}$ When $r<\bar{\mu}$, utility is not well defined when the horizon is infinite. Even when the risk-free interest rate is above the risk-adjusted growth rate, welfare gain results are not very reliable for an infinite horizon. When $H=\infty$, the gain is

$$
\frac{-0.5 \gamma d \sigma_{T}^{2}}{r-\bar{\mu}}
$$

Small changes in the estimated interest rate can then have enormous effects when $r$ is close to $\bar{\mu}$. For those reasons we assume a finite horizon in the remainder of the paper.

\footnotetext{
${ }^{8} \mathrm{It}$ is not exactly a random walk since $d y^{T W} / y^{T W}=\sum_{j=1}^{J}\left(y_{j}^{T} / y^{T W}\right)\left(\mu d t+\sigma_{T} d z_{j}\right) / J$, where the weights $y_{j}^{T} / y^{T W}$ are themselves stochastic. However, numerical analysis shows that holding the weights constant leads to practically identical expected utility. Lewis (1996a) and van Wincoop (1994) also make this approximation. There is a nice discussion in the Appendix of Lewis (1996a) on the accuracy of this approximation.

${ }^{9} \bar{\mu}$ is not much smaller than $\mu$ for reasonable levels of $\gamma$.
} 


\subsection{Data and Welfare Gain}

In order to implement (4), we need to have estimates of the risk-free interest rate, riskadjusted growth rate, rate of relative risk-aversion, the standard deviation of country endowment growth, and the correlation between endowment growth rates.

Since we are interested in potential gains from additional risksharing we use consumption rather than output data to measure the endowments. Consumption data may already reflect a certain degree of risksharing today.

Time series of tradables and non-tradables consumption for 20 OECD countries are constructed from annual data for specific consumption categories over the period 1970 to 1989. ${ }^{10}$ The data are from the United Nations National Accounts Statistics. ${ }^{11}$ The following four categories are defined as tradables consumption: (1)food, (2)clothing and footwear, (3)furniture, household equipment and operation, and (4)personal transportation. ${ }^{12}$ All other categories are defined as non-tradables consumption. They are gross rent, fuel and power; medical care and health expenses; public transportation and communication; recreation, entertainment, education and cultural services; personal care; expenditure in restaurants, cafes and hotels; and other goods and services. While no good or service is a tradable or non-tradable in the strictest sense, ${ }^{13}$ this categorization nonetheless seems a reasonable approximation. The definition of non-tradables will be important when we consider non-separable preferences in section 4. At that point we also perform sensitivity analysis with respect to the categories included in both types of consumption.

Within the assumed categorization we consider two measures of tradables consumption. The first measure simply aggregates over the four categories above and divides by population. Since there is only one tradable good in the model, all categories are assumed to be perfect substitutes. Therefore aggregate tradables consumption is defined as a linear combination over the four categories, using 1980 consumption spending

\footnotetext{
${ }^{10}$ The countries are Australia, Austria, Belgium, Canada, Denmark, Finland, France, Germany, Greece, Iceland, Ireland, Italy, Japan, Netherlands, Norway, Spain, Sweden, Switzerland, UK, US.

${ }^{11}$ An alternative data source for to constructing measures of tradables and non-tradables consumption is that used in Lewis (1996b), which is based on benchmark studies from which the Summers and Heston (1991) data set is constructed. That data set has more categories than the UN data. But it is only available at 5-year intervals since 1970, which makes it less useful for our purposes. The tests of international risksharing in Lewis (1996b) exploit the cross sectional aspect of the data.

${ }^{12}$ For Japan the UN does not publish data on category (4), personal transport. Those data are obtained from the Annual Report on National Accounts by the Economic Planning Agency, Government of Japan.

${ }^{13}$ Traded goods go through a local distribution and sales network before they reach the customer, so that the final product always has a non-tradables content. And while some sevices are primarily enjoyed by local residents, there is often some degree of trade, through tourism or otherwise.
} 
weights. ${ }^{14}$ The average standard deviation of the growth rate of per capita tradables consumption is $\sigma_{T}=3.23 \%$, with a cross country correlation of $\omega_{T}=0.21$. However, categories (2)-(4) are durables. This may lead to a significant overestimation of the gains from risksharing because spending on durables is much more volatile than the stock.

Our second measure first computes the stock of durables for each category before aggregating and dividing by population. The procedure in van Wincoop (1994) is followed to compute a time series of the stock, given data on spending flows. For food (category (1)), the stock is set equal to annual purchases (rate of depreciation of 1 ). Total tradables consumption is defined as a linear combination over the four stocks, using linear weights such that for each category the value of the 1980 service flow from durables equals 1980 spending on that category. ${ }^{15}$ For this second measure, the average standard deviation of the growth rate is $\sigma_{T}=2.01 \%$ and the average cross country correlation $\omega_{T}=0.27$.

We compute the real interest rate using annual data on money market rates from the IFS for 14 countries of the sample and subtracting the CPI inflation rate. The average is $0.85 \%$, almost identical to what Mehra and Prescott find for the much longer sample. The average growth rate of per capita consumption is $2.35 \%$, so that again the riskfree rate is lower than the consumption growth rate. We therefore set $r=0.0085$ and $\mu=0.0235$.

The rate of relative risk-aversion is a bit more difficult to measure. As can be seen from (4), given $r$ and $\bar{\mu}$, the welfare gain is proportional to the rate of relative riskaversion. In theory, almost any result can be obtained dependent on the assumption about $\gamma$. Throughout this paper we set $\gamma=3$. This is the average of the estimates reported in Friend and Blume (1975), and referred to by Shiller and Athanoulis (1995) as representing "a consensus by many who work in this literature".

For both consumption measures, Figure 1 shows the welfare gain as a function of the time horizon. For sensitivity analysis, the results are also shown for higher riskfree rates of $3.35 \%$ (so that $r-\mu=1 \%$ ) and $10 \%$. At a 50 year horizon, the gain is $3.3 \%$ for the first consumption measure and $1.18 \%$ for the second measure. Both of these numbers are sizable, especially if one compares it to the potential cost of developing financial institutions and markets to achieve the risksharing. The entire securities industry in the US amounts to no more than about $1.8 \%$ of tradables consumption. ${ }^{16}$

\footnotetext{
${ }^{14}$ The problem with using a non-linear (e.g. CES) index over individual categories is that the sum of the indices over individual countries has no interpretation as "total world consumption", unless all goods within the index move together one-for-one. The world resource constaints would have to be imposed for each category, which makes the analysis significantly more complicated and less transparant.

${ }^{15}$ In the working paper version it is shown that in steady state the value of the service flow from durables is approximately equal to the value spent on the durables.

${ }^{16}$ See Diaz-Gimenez, et.al. (1992), and the discussion in van Wincoop (1994).
} 
From now on we focus on the more conservative, and more realistic, second consumption measure. The welfare gain result reported above would be unreliable if it is very sensitive to the risk-free rate. When $r$ is raised from $0.85 \%$ to $3.35 \%$ the welfare gain drops only slightly at a 50 year horizon from $1.18 \%$ to $0.97 \%$. The results are a bit more sensitive at the very long horizon of 100 years: the welfare gain drops from $2.59 \%$ to $1.76 \%$. But it should be kept in mind that average real interest rates observed over such a long time span are much lower than 3.35\%. For very large and unrealistic interest rates, the welfare gain is significantly dampened for almost any horizon. When $r$ is raised to $10 \%$, the welfare gain does not rise much beyond a 30 year horizon, reaching only $0.55 \%$ for a 100 year horizon. This illustrates that reported welfare gains can be misleadingly low when preferences are parameterized such that the implicit risk-free rate is unrealistically large. As mentioned earlier, this is one of the reasons for the very low risksharing gains reported in Cole and Obstfeld (1991) and Obstfeld (1994b).

\subsection{Alternative Endowment Processes}

We now discuss the role of alternative stochastic processes. When considering a more complicated process than the random walk we are forced to use a discrete time approach since there is no analytical solution to the welfare gain. The gain is then approximated through numerical simulation of the processes. ${ }^{17}$ We consider five special cases of the following general processes for the tradables and non-tradables endowments:

$$
\begin{aligned}
& \frac{y_{i, t+1}^{T}-y_{i t}^{T}}{y_{i t}^{T}}=a+\theta_{T} \frac{y_{i t}^{T}-y_{i, t-1}^{T}}{y_{i, t-1}^{T}}+\eta_{T} \frac{y_{i t}^{T}}{y_{i t}^{N}}+\nu_{T} \frac{y_{i t}^{T}}{y_{t}^{T W}}+\rho_{T}\left(\ln \left(y_{i t}^{T}\right)-b t\right)+\epsilon_{i, t+1}^{T} \\
& \frac{y_{i, t+1}^{N}-y_{i t}^{N}}{y_{i t}^{N}}=a+\theta_{N} \frac{y_{i t}^{N}-y_{i, t-1}^{N}}{y_{i, t-1}^{N}}+\eta_{N} \frac{y_{i t}^{N}}{y_{i t}^{T}}+\nu_{N} \frac{y_{i t}^{N}}{y_{t}^{N W}}+\rho_{N}\left(\ln \left(y_{i t}^{N}\right)-b t\right)+\epsilon_{i, t+1}^{N}
\end{aligned}
$$

with

$$
\begin{array}{ll}
\sigma_{N}^{2}=\operatorname{var}\left(\epsilon_{i t}^{N}\right) \forall i & \sigma_{T}^{2}=\operatorname{var}\left(\epsilon_{i t}^{T}\right) \forall i \\
\omega_{N}=\operatorname{corr}\left(\epsilon_{i t}^{N}, \epsilon_{j t}^{N}\right) \forall i \neq j & \omega_{N T}=\operatorname{corr}\left(\epsilon_{i t}^{N}, \epsilon_{i t}^{T}\right) \forall i \\
\omega_{T}=\operatorname{corr}\left(\epsilon_{i t}^{T}, \epsilon_{j t}^{T}\right) \forall i \neq j & \omega_{N T}^{*}=\operatorname{corr}\left(\epsilon_{i t}^{N}, \epsilon_{j t}^{T}\right) \forall i \neq j
\end{array}
$$

The process of the non-tradables endowment matters when there are sectoral spillovers $(\eta<0)$, or when tradables and non-tradables are non-separable in utility. Non-separability is considered in the next section, where we assume the same processes.

The first special case assumes that $\theta=\eta=\nu=0$ and $\rho<0$, so that both endowments are stationary. Approximating the growth of the tradables endowment as

\footnotetext{
${ }^{17}$ Utility is now $E \sum_{t=1}^{H}\left(\frac{1}{1+\beta}\right)^{t} \frac{\left(c_{i t}^{T}\right)^{1-\gamma}}{1-\gamma}$.
} 
$\ln \left(y_{i, t+1}^{T}\right)-\ln \left(y_{i t}^{T}\right)$, the $\log$ of the tradables endowment follows an AR process around a deterministic trend, with an AR coefficient of $1+\rho .{ }^{18}$ The second process is the random walk with drift, where $\theta=\eta=\nu=\rho=0$. The third is an AR process in the growth rate of consumption $(\eta=\nu=\rho=0)$. The fourth process is also non-stationary, but assumes sectoral cointegration through the sectoral spillover parameters $\eta_{N}$ and $\eta_{T}$ $(\nu=\rho=0, \eta<0)$. The final process assumes global cointegration $(\eta=\rho=0, \nu<0)$.

Table 1 shows the results from estimating these processes. The results are based on GLS estimation on the panel of tradables and non-tradables consumption data. Standard deviations are country-specific in the estimation, although we only report (and use in the welfare gain computations) the unweighted average. The constant term and, for the stationary process, the time trend coefficient, are not reported, but are also allowed to be country specific. Nonetheless the same growth rate of $2.35 \%$ is assumed for all countries in the welfare computations.

For each of the five processes Table 2 reports various moments associated with the consumption endowments at different horizons. The reported numbers are average moments over 1000 simulations of the estimated processes. For now we are most interested in the standard deviations of country specific and global tradables consumption, reported in the upper part of the Table. They rise significantly as the horizon becomes longer. The only exception is the stationary process, where the standard deviation peaks at the 10 year horizon and remains virtually unchanged for longer horizons. This reduces substantially the potential gain from risksharing. For the global cointegration process the standard deviation of country specific consumption is much higher than for the stationary process at horizons of at least 10 years. But as a result of the global cointegration the standard deviation of country specific consumption is very close to that of the corresponding global consumption measure, especially at long horizons. This also keeps the potential welfare gain low.

Figure 2 shows the welfare gain as a function of the time horizon. The welfare gain under sectoral cointegration is practically identical to that for the AR process in growth rates and is therefore omitted from the Figure. It is assumed that $r=0.85 \%, \mu=2.35 \%$ and $\gamma=3$. While $\rho_{T}$ is estimated to be -0.19 for the stationary process, we also consider a "near random walk" stationary process where $\rho_{T}=-0.01$. In that case it is assumed that $\sigma_{T}$ and $\omega_{T}$ are the same as for the random walk process, so that the difference is only attributed to the size of $\rho_{T}$.

The welfare gain is biggest for the AR process in growth rates. The estimated AR

\footnotetext{
${ }^{18}$ We don't use this approximation here since positive and negative shocks would then affect the consumption level asymmetrically and the welfare gains from risksharing under log preferences (rate of relative risk aversion of one) would be zero.
} 
coefficient is 0.354 . Uncertainty then matters even more than for the random walk since a shock to the endowment today leads to an even larger shock to expected future endowments. The welfare gain is $2.44 \%$ for a 50 year horizon and $5.66 \%$ for a 100 year horizon. For the random walk process the welfare gain is respectively $1.13 \%$ and $2.54 \% .^{19}$ The welfare gain drops to only $0.08 \%$ for the estimated stationary process where $\rho_{T}=-0.19$. This should not be surprising given the much lower variability of consumption at horizons of 10 years or more, documented in Table 2. For the "near random walk" process the welfare gain remains quite high, although it drops significantly at long horizons. At a 100 year horizon the gain drops from $2.54 \%$ when $\rho_{T}=0$ (random walk) to $1.37 \%$ when $\rho_{T}=-0.01$. For the global cointegration process the welfare gain is approximately $0.20 \%$ for horizons of at least 10 years. In this case countries soon catch up to each other even in the absence of trade in the consumption endowments.

Which of these processes is most realistic? Table 3 reports results from a panel version of the augmented Dickey-Fuller unit root test, developed by Im, Pesaran, and Shin (1995). The reported test statistic follows a standard normal distribution under the null of a unit root. If we look at the results with three augmentation lags, the tests do not reject a unit root in tradables and non-tradables consumption. Evidence of a unit root is weaker for tradables consumption though, where it is rejected with two augmentation lags. There is also evidence against global cointegration, although again stronger for non-tradables than tradables. And finally, we cannot reject a unit root in $\ln c^{N}-\ln c^{T}$, which is evidence against sectoral cointegration. While this evidence is generally in favor of either the random walk or the AR in growth rates, it should be stressed that with only twenty years of data unit root tests are not very informative.

A more promising approach to distinguish the empirical relevance of the various processes is to use direct evidence on growth uncertainty from empirical growth regressions. The convergence literature has estimated cross country regressions of growth on initial per capita GDP. For example, De Long (1988) reports results of a cross country regression of $\ln y_{1979}-\ln y_{1870}$ on a constant and $\ln y_{1870}$. De Long is careful in choosing an unbiased sample of countries. He argues that choosing countries that are rich today, and therefore have ex-post converged, leads to a strong bias in favor of finding convergence. 20 De Long therefore chooses a sample of the 22 richest countries in 1870, some of which do not belong to the richest countries today. He finds a standard error of the regression of 0.21 . Since this is a cross-section regression, the standard error is a measure of the

\footnotetext{
${ }^{19}$ The $1.13 \%$ gain for a 50 year horizon is slightly below the $1.18 \%$ reported earlier because now a discrete time rather than a continuous time approach is used.

${ }^{20}$ In this respect he criticizes Baumol (1988), who finds rapid convergence over the period 1870-1979 for a sample of countries that are currently rich.
} 
uncertainty about the log of future per capita output relative to that of the "world" (the aggregate of the countries in the sample).

We can compare this to the standard deviations of $\ln c^{T}-\ln c^{T W}$ and $\ln c^{N}-$ $\ln c^{N W}$ with an horizon of 100 years, reported in Table 2. These are, respectively, 0.025 and 0.02 for the stationary process. This is only one tenth of the 0.21 standard error reported by De Long (1988), which provides strong evidence against the stationary process. The welfare gain based on the stationary process is best interpreted as the gain from sharing temporary business cycle shocks, which leave the world distribution of wealth practically unchanged at longer horizons. For the global cointegration process the standard deviations are also very low, respectively 0.041 and 0.044 , about one fifth of the standard errors in De Long (1988). The global cointegration hypothesis, combined with quite negative estimated values for $\nu_{N}$ and $\nu_{T}$ (-0.077 and -0.109), implies that the world distribution of wealth is far more predictable than observed in the data. For the other non-stationary processes the evidence is roughly consistent with the data. For the random walk the standard deviations of $\ln c^{T}-\ln c^{T W}$ and $\ln c^{N}-\ln c^{N W}$ are, respectively, 0.16 and 0.15 . These standard deviations are 0.24 and 0.20 for the AR process in growth rates, and close to that for the sectoral cointegration process. Thus, strong evidence exists that these processes generate a realistic degree of uncertainty about long run growth. ${ }^{21}$

Further evidence to support this comes from Athanasoulis and van Wincoop (1997), who estimate growth uncertainty as a function of the horizon and the information set used to predict growth. Defining growth as the change in the log of per capita GDP, they regress country growth, in deviation from world growth, on variables in the information set. For a set of 21 OECD countries, using an information set consisting of the three most informative variables ${ }^{22}$ out of a set of 21 variables used frequently in the empirical growth literature, the standard deviation of the growth innovation at a 35-year horizon is 0.15 (using data from 1955 to 1990). ${ }^{23}$ Additional variables do not further improve the predictability of growth at that horizon. ${ }^{24}$ The estimated standard deviation at a 35-year horizon remains 0.15 when per capita consumption is used as a measure for the

\footnotetext{
${ }^{21}$ For the "near random walk" process, the standard deviations at a 100 year horizon are significantly lower than for the random walk: 0.11 and 0.10 for $\ln c^{T}-\ln c^{T W}$ and $\ln c^{N}-\ln c^{N W}$.

${ }^{22}$ These are the $\log$ of initial per capita GDP, enrollment in higher education, and the fertility rate.

${ }^{23}$ For an historical sample from 1870 to 1990 , they find that the standard deviation over a 120 year horizon is 0.20 for the eight richest countries in 1870, with an information set consisting of the log of initial per capita GDP and the fertility rate. This is almost the same as what De Long finds for a set of 22 countries.

${ }^{24}$ The estimated standard deviation even rises a bit, to 0.16 , for a so-called "base-information set" of 13 variables.
} 
endowment, as in this paper.

The information sets considered in Athanasoulis and van Wincoop (1997) are inconsistent with the processes considered in this paper, and it is likely that some complicated multivariate process better describes the data. But what is more important is that we choose a process that has similar implications for long term growth uncertainty. This is indeed the case for the AR process in growth rates and the sectoral cointegration process. For both, the standard deviation of $\ln c^{T}-\ln c^{T W}$ is 0.13 for a 30-year horizon and 0.17 for a 50 -year horizon. The random walk process may even underestimate growth uncertainty somewhat because the standard deviation of $\ln c^{T}-\ln c^{T W}$ is 0.09 and 0.12 for, respectively, a 30 and 50-year horizon (and the same for the non-traded goods endowment).

To summarize, the random walk process, the AR process in growth rates, and the sectoral cointegration process are most consistent with empirical evidence on long term growth uncertainty. This leads to a sizable welfare gain, ranging from $1.13 \%$ to $2.44 \%$ for a 50 year horizon, and $2.54 \%$ to $5.66 \%$ for a 100 year horizon.

\section{Non-Separable Preferences}

The role of non-separability between traded and non-traded goods has received relatively little attention in the welfare gain literature so far. An exception is Tesar (1995), who provides some results for a two country case when the endowments are stationary. ${ }^{25}$

While it is impossible to trade claims on the output of the non-traded goods sector itself, in optimal risksharing contracts the transfer of tradables is generally contingent on output in the non-traded goods sector. We now explore the implications of such contracts for the gains from risksharing.

\subsection{The Setup}

Utility of a representative agent from country $i$ is

$$
E \sum_{t=1}^{H}\left(\frac{1}{1+\beta}\right)^{t} \frac{c_{i t}^{1-\gamma}}{1-\gamma},
$$

\footnotetext{
${ }^{25}$ There are many related papers though. Tesar (1993) finds that the presence of non-traded goods may help account for the low cross country consumption correlations. Lewis (1996b) tests the perfect risksharing hypothesis when allowing for non-separability between traded and non-traded goods. There is also some work, by Baxter, Jermann and King (1994), Eldor, Pines and Schwartz (1988), Ghosh and Pesenti (1994), Pesenti and van Wincoop (1996), and Serrat (1996), on the role of non-traded goods for international portfolio diversification. None of these papers compute the potential gains from risksharing.
} 
where the total consumption index $c$ is defined as a CES index of tradables and nontradables consumption:

$$
c_{i t}=\left(\alpha\left(c_{i t}^{T}\right)^{1-1 / \epsilon}+(1-\alpha)\left(c_{i t}^{N}\right)^{1-1 / \epsilon}\right)^{\epsilon /(\epsilon-1)}
$$

Here $\epsilon$ is the contemporaneous elasticity of substitution between tradables and nontradables. At $c_{i t}^{T}=c_{i t}^{N}, \alpha$ measures the fraction spent on tradables. Preferences are non-separable as long as $\epsilon \gamma \neq 1 .{ }^{26}$

We consider the same set of endowment processes as in section 3.3. Before risksharing agents simply consume their endowments: $c_{i t}^{T}=y_{i t}^{T}$ and $c_{i t}^{N}=y_{i t}^{N}$. Since all countries are ex-ante identical, the equilibrium under perfect risksharing can be found by maximizing

$$
E \sum_{i=1}^{J} \sum_{t=1}^{H}\left(\frac{1}{1+\beta}\right)^{t} \frac{c_{i t}^{1-\gamma}}{1-\gamma}
$$

s.t.

$$
\begin{array}{r}
c_{i t}^{N}=y_{i t}^{N} \forall i, t \\
\sum_{i=1}^{J} c_{i t}^{T}=\sum_{i=1}^{J} y_{i t}^{T} \forall t
\end{array}
$$

The first order conditions from this maximization are:

$$
\alpha c_{i t}^{-\gamma}\left(\frac{c_{i t}^{T}}{c_{i t}}\right)^{-1 / \epsilon}=\lambda_{t} \forall i, t
$$

Here $\lambda_{t}$ is the utility shadow value of a marginal unit of tradables endowment. Under perfect risksharing the marginal utility from tradables consumption is the same in all countries in each period. Eqn.(7) provides an implicit expression for the consumption of tradables in country $i$ as a function of non-tradables consumption and $\lambda_{t}$ :

$$
c_{i t}^{T}=F\left(c_{i t}^{N}, \lambda_{t}\right)
$$

This function is monotonically decreasing in $\lambda$. Imposing the world endowment constraint for tradables consumption, we can solve for $\lambda_{t}$ and tradables consumption as a function of the world endowment of tradables and each country's non-tradables consumption. Since we cannot solve (7) explicitly, a numerical method is used to approximate the precise solution. Using Newton's method, for each period a search is done over $\lambda_{t}$ and for a given $\lambda_{t}$ over $c_{i t}^{T} \forall i$, until a convergence criterion is satisfied. Details of the numerical method can be found in Appendix A.

\footnotetext{
${ }^{26} \mathrm{~A}$ previous version of the paper also considers non-expected utility preferences, so that there are three utility parameters: the rate of relative risk-aversion, the intertemporal elasticity of substitution of consumption, and the intratemporal elasticity of substitution between the two consumption goods. It is shown for the case of random walk that, for a given interest rate, the welfare gain is the same as under expected utility preferences, so that this generalization does not change the findings reported below.
} 


\subsection{Some Approximate Results: Quadratic Utility}

Before implementing the numerical solution method outlined above, it is useful to first discuss the optimal risksharing rule, and associated welfare gain, for a second order approximation of the utility function. Under quadratic utility explicit analytical results can be derived, which turn out useful when interpreting the numerical results based on utility function (5)-(6).

Replace the time $t$ subutility $U=c_{i t}^{1-\gamma} /(1-\gamma)$ of the representative consumer of country $i$ by its second order Taylor expansion around the expected consumption levels of both goods. Omitting the constant term, we obtain:

$$
\begin{aligned}
& U_{N}\left(c_{i t}^{N}-E c_{i t}^{N}\right)+U_{T}\left(c_{i t}^{T}-E c_{i t}^{T}\right)+0.5 U_{N N}\left(c_{i t}^{N}-E c_{i t}^{N}\right)^{2}+ \\
& 0.5 U_{T T}\left(c_{i t}^{T}-E c_{i t}^{T}\right)^{2}+U_{N T}\left(c_{i t}^{N}-E c_{i t}^{N}\right)\left(c_{i t}^{T}-E c_{i t}^{T}\right)
\end{aligned}
$$

Here $U_{i}$ is the derivative of the subutility $U$ with respect to consumption of good $i$, measured at $c_{i t}^{N}=E c_{i t}^{N}$ and $c_{i t}^{T}=E c_{i t}^{T}$. Second order derivatives are defined similarly. Without loss of generality assume that $E c_{i t}^{N}=E c_{i t}^{T}=1$, so that $\alpha$ measures the fraction spent on tradables, and $U_{T}=\alpha, U_{N}=1-\alpha, U_{T T}=-\alpha[\alpha \gamma+(1-\alpha)(1 / \epsilon)], U_{N N}=$ $-(1-\alpha)[\alpha \gamma+(1-\alpha)(1 / \epsilon)], U_{N T}=\alpha(1-\alpha)[1 / \epsilon-\gamma]$.

The first order condition ( 7 ) is now replaced by

$$
U_{T}+U_{T T}\left(c_{i t}^{T}-E c_{i t}^{T}\right)+U_{N T}\left(c_{i t}^{N}-E c_{i t}^{N}\right)=\lambda_{t}
$$

We can solve for $\lambda_{t}$ by aggregating over countries and imposing the constraint that world consumption of tradables equals the world endowment. Substituting this equilibrium value for $\lambda_{t}$ back into (10), we get

$$
c_{i t}^{T}=y_{i t}^{T W}-\frac{U_{N T}}{U_{T T}}\left(y_{i t}^{N}-y_{i}^{N W}\right)=y_{t}^{T W}+\frac{(1-\alpha)(1-\epsilon \gamma)}{1-\alpha+\alpha \epsilon \gamma}\left(y_{i t}^{N}-y_{t}^{N W}\right)
$$

When $\epsilon \gamma=1$, utility is additively separable in tradables and non-tradables, and the standard result applies that consumption of tradables equals the per capita world endowment of tradables. When $\epsilon \gamma<1$, the two goods are complements. An increase in non-tradables consumption raises the marginal utility from tradables consumption. Under perfect risksharing, a country that is faced with an average endowment of tradables, but a non-tradables endowment above the world average, will then receive a transfer of tradables from the rest of the world. The optimal risksharing arrangement therefore raises the correlation between tradables and non-tradables consumption. The opposite is the case when the goods are substitutes $(\epsilon \gamma>1)$.

The following proposition, which is proven in the appendix, is useful in interpreting the numerical welfare gain results below. 
Proposition 1 Assume that $\operatorname{var}\left(y_{i t}^{N}\right)=\operatorname{var}\left(y_{i t}^{T}\right)$ and $\operatorname{var}\left(y_{t}^{N W}\right)=\operatorname{var}\left(y_{t}^{T W}\right)$. Then the welfare gain from international risksharing associated with the period $t$ endowments is smaller for $\epsilon \gamma \neq 1$ than $\epsilon \gamma=1$ iff:

$$
\begin{aligned}
& \epsilon \gamma<1(>1) \text { and } \frac{0.5 \epsilon \gamma}{1-\alpha+\alpha \epsilon \gamma}+K>(<) m \\
& \text { where } K=\frac{\operatorname{corr}\left(y_{t}^{N W}, y_{t}^{T W}\right)-\operatorname{corr}\left(y_{i t}^{N}, y_{i t}^{T}\right)}{\left(\operatorname{var}\left(y_{i t}^{T}\right) / \operatorname{var}\left(y_{t}^{T W}\right)\right)-1} \\
& m=1+K-\operatorname{corr}\left(y_{i t}^{N}, y_{i t}^{T}\right)
\end{aligned}
$$

As can be seen from Table 2, the proposition's assumption that non-tradables consumption is about equally volatile as tradables consumption, both at the country and global level, is approximately true in the data.

The proposition is illustrated in Figure 3, in which the areas where the welfare gain is larger under separable preferences are shaded. Most relevant to us is the area where $m<0.5$ because it follows from Table 2 that $K$ lies somewhere between 0 and 0.1 , while the correlation between tradables and non-tradables consumption is always quite high, somewhere between 0.65 and 0.96. As we can see from Figure 3, assuming $m<0.5$, the only case where the welfare gain is lower under non-separable preferences is when tradables and non-tradables are "weak" complements: $\epsilon<1 / \gamma$, but not too small.

The interpretation is as follows. When tradables and non-tradables are substitutes, the marginal utility from tradables consumption drops if non-tradables consumption rises. In that case large gains can be reaped from engaging in a risksharing contract that significantly reduces the correlation between both types of consumption relative to the high correlation between the endowments. When the two goods are complements, agents favor a large positive correlation between consumption of traded and non-traded goods. Therefore they may already be very satisfied with the high correlation between the endowments before risksharing, leading to small potential welfare gains. ${ }^{27}$ For sufficiently strong complementarity ( $\epsilon$ small enough), agents benefit significantly from engaging in a risksharing contract that generates an even higher correlation between consumption of the two goods.

\subsection{Welfare Gain under Non-Separable Preferences}

Figure 4 displays the welfare gain for all five processes as a function of the elasticity of substitution between tradables and non-tradables. It is assumed that $r=0.85 \%$, $\mu=2.35 \%$, and $\gamma=3$. The parameter $\alpha$ is set at 0.46 , the average fraction spent

\footnotetext{
${ }^{27}$ This is consistent with Tesar (1995), who finds that "as the endowments of traded and non-traded goods become more correlated, the benefits from trading on international markets decrease".
} 
on tradables in 1980 over all the countries in the sample. The welfare gain is shown separately for a 50 and 100 year horizon. ${ }^{28}$

The welfare gains shown in Figure 4 are defined in such a way as to make them comparable to those reported in section 3 and those previously reported in the literature. The welfare gain is defined as the value in terms of tradables that the total expected endowment must be raised each period in order to generate an equal welfare improvement as generated by perfect risksharing, divided by the expected value of tradables consumption. Under separability this is equal to the percentage increase in the tradables endowment. ${ }^{29}$

Figure 4 shows that the welfare gain is almost always higher under non-separable preferences than under separable preferences. The only exception is the sectoral cointegration process. For the other processes the value of $m$ is close to 0.4. As indicated in Figure 3, the gain is then only higher under separability for values of $\epsilon$ slightly below $1 / 3$. This is confirmed in Figure 4. But even in those cases the welfare gain under non-separable preferences is practically identical to that under separable preferences. For the sectoral cointegration process the value of $m$ is much smaller: 0.08 for a 100 year horizon and 0.05 for a 50 year horizon. From Figure 3 we see that then the welfare gain is lower under non-separability for a much wider range of values of $\epsilon$ below $1 / 3$. Intuitively, the very high correlation between the two endowments under sectoral cointegration is desirable when the goods are complements, reducing the potential gain from risksharing. But Figure 4 shows that even in this case the welfare gain is never reduced more than $30 \%$ under non-separable preferences, and much less so for a 50 year horizon.

Figure 4 further strengthens the finding based on separable preferences that the welfare gain is large or even very large, unless the process is stationary or there is global cointegration. Since it was argued that the other three processes are most realistic in terms of long term growth uncertainty, we now ask which of the gains reported for those processes is most realistic. This requires an estimate of $\epsilon$. Ostry and Reinhart (1991) estimate this elasticity to be 0.44. Pesenti and van Wincoop (1996) obtain an estimate for $\epsilon$ through panel estimation of the difference between the consumption growth rates in the two sectors on the growth rate of the relative price. The point estimate is 0.19 , with a small standard error of 0.03 . When $\gamma=3$, the estimates in Lewis (1996b) imply an intertemporal elasticity of substitution of 0.33 . She cannot reject that preferences

\footnotetext{
${ }^{28}$ The welfare gain numbers are based on 200 simulations of a 50 or 100 year period for 20 countries. The results are practically the same for a larger number of simulations.

${ }^{29}$ If one wishes to define the welfare improvement as the expected percentage increase in total consumption each period that generates the same welfare improvement, the numbers would have to be multiplied by $\alpha$ (lowered by $54 \%$ ).
} 
are separable in tradables and non-tradables. To summarize, $\epsilon$ is most likely somewhere between 0.1 and 0.5. When $\gamma=3, \epsilon$ between 0.1 and 0.5 , and any of the three favored processes applies, the welfare gain is within the range of $1.1 \%$ to $3.5 \%$ for a 50 year horizon and between $2.5 \%$ and $7.4 \%$ for a 100 year horizon. ${ }^{30}$

\section{Summary and Conclusions}

The paper has documented the extent to which potential welfare gains from international risksharing are sensitive to the parameterization of preferences and to assumptions about the stochastic process and measurement of the endowment. The parameterization of preferences is relevant in that it affects the implicit risk-free interest rate, rate of relative risk-aversion, and the elasticity of substitution between tradables and non-tradables. In order to obtain a more precise range within which potential welfare gains are likely to fall, we have used as much information as possible on the various factors determining the benefits from riskpooling. It is found that the potential gains are quite sizable, in the range of 1.1 to $3.5 \%$ for a 50 year horizon, and $2.5 \%$ to $7.4 \%$ for a 100 year horizon.

The large welfare gains reported in the paper are probably even on the conservative side for various reasons. First, there are likely to be secondary level benefits once risksharing is achieved. Obstfeld (1994a) points out that individuals will invest more in high risk, high expected return assets if the risk can be diversified. He shows that this raises growth, and documents significant additional gains. Devereux and Lee (1997) show that there are additional gains in terms of reduced trade barriers. Once agents have diversified claims on endowments of different goods, governments have no incentive to change the terms of trade through optimal tariffs. Second, Sampson (1993) shows that the cost of uncertainty is even larger when the parameters of the growth process are unknown due to a change in regime. Third, we have focused on industrialized countries, but Kose (1995), Obstfeld (1994c) and Athanasoulis and van Wincoop (1997) have shown that potential gains from risksharing can be even much larger among developing countries. Fourth, the equity premium puzzle remains unresolved. Although it was pointed out that there is not necessarily a direct relationship between the equity premium and the welfare gain, to the extent that there exists such a relationship it is likely to be positive. A higher rate of risk-aversion raises both the equity premium and the welfare

\footnotetext{
${ }^{30}$ As a final excercise, the welfare gains are also computed for two alternative measures of non-tradables consumption. One includes the categories "recreation, entertainment, education and cultural services", and "hotels, restaurants and cafes" under tradables rather than non-tradables consumption. The second is a broader definition of non-tradables, including all government consumption. Under neither of these alternatives are the results substantially different from those reported in Figure 4.
} 
gain. Finally, an increase in risksharing will also likely lead to an improved performance of financial markets with respect to its two other functions, consumption smoothing and optimal resource allocation, as it is hard to separate these various roles in practice.

If potential gains are so significant, the natural question that must be addressed in future research is why financial markets have not achieved more risksharing. We need to better understand both why investors do not take diversified positions in existing stock and bond markets, and why markets that allow for trade in broad claims on national income (macro markets) have not yet developed. 


\section{APPENDIX A: Numerical Solution Method}

The following numerical solution method is used to approximate the precise solution to the perfect risksharing equilibrium. For each period we need to solve for $\lambda_{t}$, and given $\lambda_{t}$ for $c_{i t}^{T} \forall i$. Define $x_{i t}^{s}=c_{i t}^{s} / y_{t}^{T W} s=N, T$, and $x_{i t}=c_{i t} / y_{t}^{T W}$. For a given $\lambda_{t}$ we solve $x_{i t}^{1-\gamma \epsilon} / x_{i t}^{T}=\lambda_{t}$ when $\epsilon=0.01$, and $x_{i t}^{-1+1 /(\gamma \epsilon)}\left(x_{i t}^{T}\right)^{-1 /(\gamma \epsilon)}=\lambda_{t}$ when $\epsilon>0.01$. These transformations of (7) are chosen in order to make $\lambda_{t}$ a more smooth function of $c_{i t}^{T}$, which speeds up convergence. For any given $\lambda_{t}$ the starting value in solving for $x_{i t}^{T}$ is (11), divided by $y_{t}^{T W}$. Newton's method is used to solve for $x_{i t}^{T}$. The convergence criterion is that $x_{i t}^{T}$ changes by less than $0.01 \%$ in the last iteration. For each period $\lambda_{t}$ is found as a root of the equation $\sum_{i=1}^{J} x_{i t}^{T}\left(x_{i t}^{N}, \lambda_{t}\right)-\sum_{i=1}^{J} y_{i t}^{T} / y_{t}^{T W}=0$. Newton's method is used again to search over $\lambda_{t}$. When $\epsilon>0.01$ the starting value is chosen to be 1 . When $\epsilon=0.01$ the starting value is the average of $\lambda\left(x_{i t}, x_{i t}^{T}\right)$ over all countries, where $x_{i t}^{T}$ is the starting value described above. The convergence criterion is that the world consumption of tradables is within $0.01 \%$ of the world endowment of tradables.

\section{APPENDIX B: Proof of Proposition 1}

The expected period $t$ subutility is

$$
0.5 U_{N N} \operatorname{var}\left(c_{i t}^{N}\right)+0.5 U_{T T} \operatorname{var}\left(c_{i t}^{T}\right)+U_{N T} \operatorname{cov}\left(c_{i t}^{N}, c_{i t}^{T}\right)
$$

The welfare gain can be expressed as the equal percentage increase in both tradables and non-tradables consumption that yields the same welfare improvement as generated by international risksharing. Since $U_{N}+U_{T}=1$, from (9) an $x \%$ increase in expected consumption of both goods raises the period $t$ expected subutility by approximately $x$. The welfare gain from risksharing associated with period $t$ endowments can then be measured as the increase in (12) due to risksharing. We therefore need to evaluate (12) at the risksharing allocation $c_{i t}^{T}=y_{t}^{T W}-\frac{U_{N T}}{U_{T T}}\left(y_{i t}^{N}-y_{t}^{N W}\right), c_{i t}^{N}=y_{i t}^{N}$ and subtract expected utility at the autarky allocation $c_{i t}^{T}=y_{i t}^{T}, c_{i t}^{N}=y_{i t}^{N}$ :

$$
\begin{array}{r}
\text { gain }=0.5 U_{T T} \operatorname{var}\left(y_{t}^{T W}-\frac{U_{N T}}{U_{T T}}\left(y_{i t}^{N}-y_{t}^{N W}\right)\right)+U_{N T} \operatorname{cov}\left(y_{i t}^{N}, y_{t}^{T W}-\frac{U_{N T}}{U_{T T}}\left(y_{i t}^{N}-y_{t}^{N W}\right)\right) \\
-0.5 U_{T T} \operatorname{var}\left(y_{i t}^{T}\right)-U_{N T} \operatorname{cov}\left(y_{i t}^{N}, y_{i t}^{T}\right)
\end{array}
$$

Since global variables are uncorrelated with deviations of country specific variables from their global counterpart, we have: $\operatorname{cov}\left(y_{t}^{T W}, y_{i t}^{N}-y_{t}^{N W}\right)=0, \operatorname{var}\left(y_{i t}^{N}-y_{t}^{N W}\right)=\operatorname{var}\left(y_{i t}^{N}\right)-$ $\operatorname{var}\left(y_{t}^{N W}\right), \operatorname{cov}\left(y_{i t}^{N}, y_{t}^{T W}\right)=\operatorname{cov}\left(y_{t}^{N W}, y_{t}^{T W}\right), \operatorname{cov}\left(y_{i t}^{N}, y_{i t}^{N}-y_{t}^{N W}\right)=\operatorname{var}\left(y_{i t}^{N}\right)-\operatorname{var}\left(y_{t}^{N W}\right)$. Applying this to the expression for the gain above, we get:

$$
\text { gain }=0.5 u_{T T} \operatorname{var}\left(y_{t}^{T W}\right)+0.5 \frac{U_{N T}^{2}}{U_{T T}}\left(\operatorname{var}\left(y_{i t}^{N}\right)-\operatorname{var}\left(y_{t}^{N W}\right)\right)+U_{N T} \operatorname{cov}\left(y^{T W}, y^{N W}\right)
$$




$$
-\frac{U_{N T}^{2}}{U_{T T}}\left(\operatorname{var}\left(y_{i t}^{N}\right)-\operatorname{var}\left(y_{t}^{N W}\right)\right)-0.5 U_{T T} \operatorname{var}\left(y_{i t}^{T}\right)-U_{N T} \operatorname{cov}\left(y_{i t}^{N}, y_{i t}^{T}\right)
$$

After rewriting this simplifies to

$$
0.5 U_{T T}\left[\operatorname{var}\left(y_{t}^{T W}+\frac{U_{N T}}{U_{T T}} y_{t}^{N W}\right)-\operatorname{var}\left(y_{i t}^{T}+\frac{U_{N T}}{U_{T T}} y_{i t}^{N}\right)\right]
$$

When $U_{N T}=0$, so that utility is separable in tradables and non-tradables, the welfare gain is

$$
0.5 \alpha \gamma\left[\operatorname{var}\left(y_{i t}^{T}\right)-\operatorname{var}\left(y_{t}^{T W}\right)\right]
$$

In order to judge whether non-separability of preferences raises or lowers the welfare gain, we must compare (13) with $U_{N T} \neq 0$ to (14). After substituting $U_{T T}=-\alpha[\alpha \gamma+$ $(1-\alpha)(1 / \epsilon)], U_{N T}=\alpha(1-\alpha)[1 / \epsilon-\gamma]$, and rewriting, this leads to proposition 1. 
Work on this paper was initiated while I was a visitor at the Institute for International Economic Studies in Stockholm and a research fellow at the Innocenzo Gasparini Insitute for Economic Research in Milan. I would like to thank both institutes for their hospitality. An earlier version of the paper was presented at the NBER international macro workshop and the SEDC meetings in Mexico City. I also thank Bob Cumby and two anonymous referees for many helpful comments and suggestions, and Sairah Burki for proof-reading the document. Financial support from the European Community under the Human Capital Mobility Program is gratefully acknowledged. The views expressed in the paper are those of the author and do not necessarily reflect the position of the Federal Reserve Bank of New York or the Federal Reserve System.

\section{REFERENCES}

Athanasoulis, S. and E. van Wincoop, 1997, Growth uncertainty and risksharing, Staff Reports 30, Federal Reserve Bank of New York.

Backus, D.K., Kehoe, P.J. and F.E. Kydland, 1992, International real business cycles, Journal of Political Economy 100, 745-775.

Baxter, M., U.J. Jermann and R.G. King, 1994, Non-traded goods, non-traded factors and international non-diversification, working paper, University of Virginia.

Baumol, W.J., 1986, Productivity growth, convergence and welfare: what the long-run data show, American Economic Review 76 (51), 1072-1085.

Brennan, M.J., and B. Solnik, 1989, International risksharing and capital mobility, Journal of International Money and Finance 8, 359-373.

Canova, F. and M.O. Ravn, 1996, International consumption risk sharing, International Economic Review 37, 573-601.

Cole, H.L. and M. Obstfeld, 1991, Commodity trade and international risksharing: how much do financial markets matter?, Journal of Monetary Economics 28, 3-24.

Crucini, M.J., 1996, On international and national dimensions of risksharing, working paper, Ohio State University.

De Long, J.B., 1988, Productivity growth, convergence and welfare: a comment, American Economic Review 78, 1138-1154.

Devereux, M.D. and G.W. Smith, 1994, International risksharing and economic growth, International Economic Review 35, 335-50. 
Devereux, M.B. and K.M. Lee, 1997, Endogenous trade policy and the gains from international financial markets, working paper, University of British Columbia.

Diaz-Gimenez, J., E.C. Prescott, T. Fitzgerald, and F. Alvarez, 1992, Banking in computable general equilibrium economies, Federal Reserve Bank of Minneapolis, Staff Report 153.

Eldor, R., Pines, D. and A. Schwartz, 1988, Home asset preference and productivity shocks, Journal of International Economics 25, 165-76.

French, K.R. and J.M. Poterba, 1991, Investor diversification and international equity markets, American Economic Review, Papers and Proceedings 81, 222-26.

Friend, I. and M.E. Blume, 1975, The demand for risky assets, American Economic Review 65, 900-922.

Ghosh, A.R. and P. Pesenti, 1994, International portfolio diversification, non-tradable incomes and consumption growth: some puzzles and interpretations, working paper, Princeton University.

Im, Kyungso, M. Hashem Pesaran, and Yongcheol Shin, 1995, Testing for unit roots in heterogeneous panels, working paper, Department of Applied Economics, University of Cambridge.

Kose, M.A., 1995, Welfare Implications of international risk sharing, working paper, University of Iowa.

Lewis, K.K., 1996a, Consumption, stock returns, and the gains from international risksharing, NBER Working Paper no. 5410.

Lewis, K.K., 1996b, What can explain the apparant lack of international consumption risksharing?, Journal of Political Economy 104(2), 267-297.

Lucas, R.E., 1987, Models of business cycles (Blackwell ,Oxford).

Mehra, R. and E.C. Prescott, 1985, The equity premium: a puzzle, Journal of Monetary Economics 15, 145-161.

Mendoza, E., 1995, The terms of trade, the real exchange rate and economic fluctuations, International Economic Review 36, 101-137.

Obstfeld, M., 1992 , International risksharing and capital mobility: another look, Journal of International Money and Finance 11, 115-121. 
Obstfeld, M., 1994a, Risk-taking, global diversification, and growth, American Economic Review 84, 1310-1329.

Obstfeld, M., 1994b, Evaluating risky consumption paths: the role of intertemporal substitutability, European Economic Review 38, 1471-86.

Obstfeld, M., 1994c, Are industrial-country consumption risks globally diversified? in: L. Leiderman and A. Razin, eds, Capital mobility: the impact on consumption, investment and growth (Cambridge University Press, Cambridge) 13-47.

Obstfeld, M., 1995, International capital mobility in the 1990s, in: P.B. Kenen, ed., Understanding interdependence ( Princeton University Press, Princeton) 201-261.

Pesenti, P. and E. van Wincoop, 1996, International portfolio diversification and nontraded goods, NBER Working paper no. 5784.

Sampson, M., 1993, The welfare implications of parameter uncertainty for stabilization policy, working paper, Concordia University.

Serrat, A., 1996, A dynamic equilibrium model of international risk-sharing puzzles, working paper, Sloan School of Management, MIT.

Shiller, R.J., 1993, Macro markets: creating institutions for managing society's largest economic risks (Clarendon Press, Oxford).

Shiller, R.J. and S. Athanasoulis, 1995, World income components: measuring and exploiting international risk sharing opportunities, NBER Working Paper no. 5095.

Summers, R. and A. Heston, 1991, The Penn World Table (mark 5): an expanded set of international comparisons, 1950-1988, Quarterly Journal of Economics 106, 327-368.

Tesar, L.L., 1995, Evaluating the gains from international risksharing, Carnegie-Rochester Conference Series on Public Policy 42, 95-143.

Tesar, L.L., 1993, International risksharing and nontraded goods, Journal of International Economics 35, 69-89.

Tesar, L.L., and I.M. Werner, 1994, International equity transactions and US portfolio choice, in: J.A. Frankel, ed., The internationalization of equity markets (University of Chicago Press, Chicago) 185-216.

Tesar, L.L. and I.M. Werner, 1995, Home bias and high turnover, Journal of International Money and Finance 14, 467-492. 
van Wincoop, E., 1994, Welfare gains from international risksharing, Journal of Monetary Economics 34, 175-200.

van Wincoop, E., 1995, Regional risksharing, European Economic Review 37, 1545-1567. van Wincoop, E., 1996, A multi-country real business cycle model with heterogeneous agents, Scandinavian Journal of Economics 98, 233-251. 


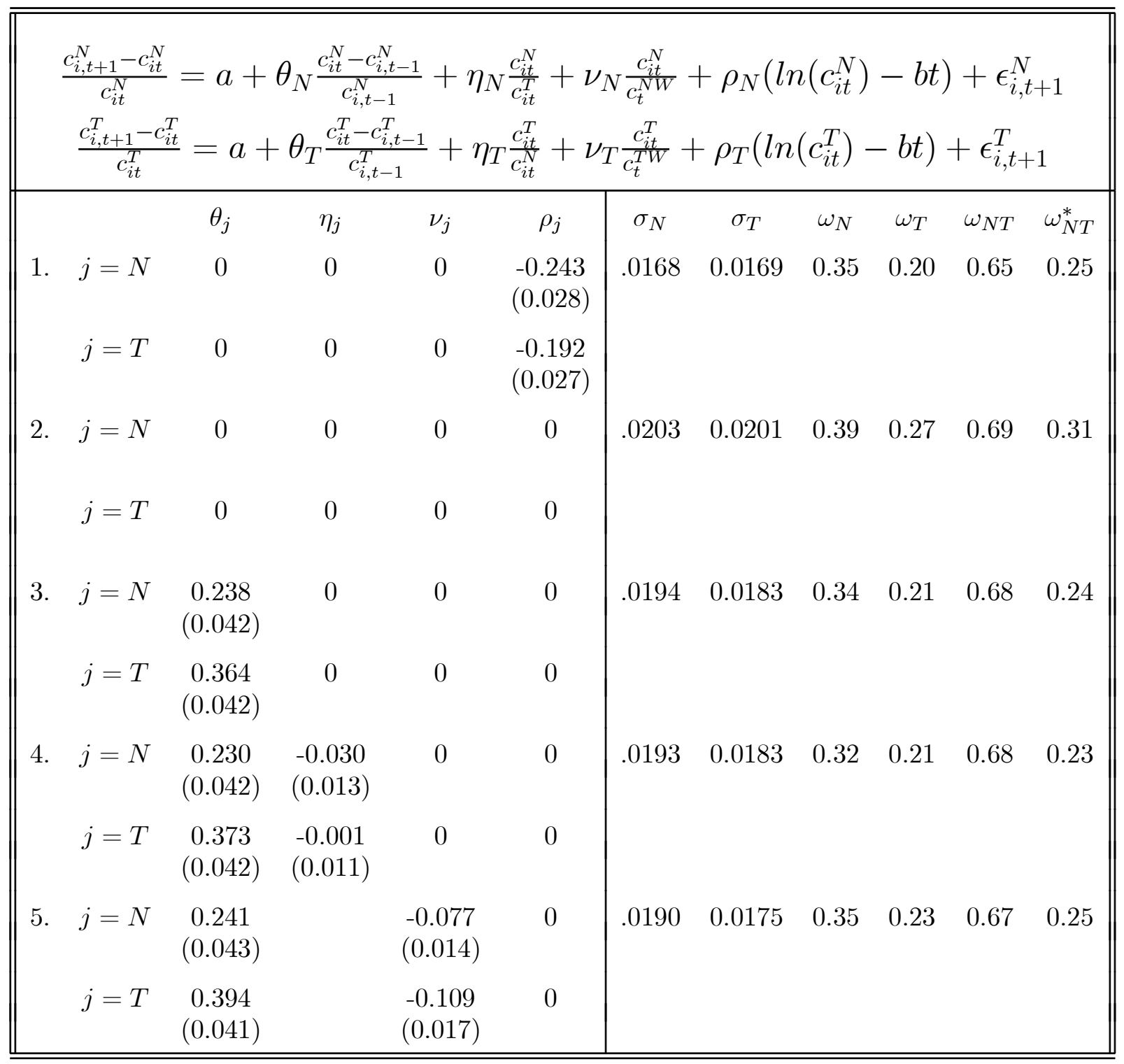

Table 1: Estimated processes for tradables and non-tradables consumption

Notes : Five restricted forms of the equations listed in upper part of the Table are estimated by GLS on a panel data set for 20 OECD countries with annual data from 1970 to 1989. The measure of tradables consumption that corrects for durability is used. It is assumed that $\omega_{N}=\operatorname{corr}\left(\epsilon_{i t}^{N}, \epsilon_{j t}^{N}\right), \omega_{T}=\operatorname{corr}\left(\epsilon_{i t}^{T}, \epsilon_{j t}^{T}\right), \omega_{N T}=\operatorname{corr}\left(\epsilon_{i t}^{T}, \epsilon_{i t}^{N}\right)$, $\omega_{N T}^{*}=\operatorname{corr}\left(\epsilon_{i t}^{T}, \epsilon_{j t}^{N}\right)$ are equal across countries or sets of countries. The standard deviations of the innovations, $\sigma_{N}$ and $\sigma_{T}$ are country specific in the estimation, but only their unweighted average is reported (and used in the welfare gain computations). The five estimated processes are: (1) stationary process, (2) random walk process (3) AR process in growth rates, (4) non-stationary process with sectoral cointegration, and (5) non-stationary process with global cointegration. 


\begin{tabular}{|c|c|c|c|c|c|c|c|c|c|c|c|c|c|c|c|}
\hline & \multicolumn{5}{|c|}{ Standard Deviation $\ln c^{T}$} & \multicolumn{5}{|c|}{ Standard Deviation $\ln c^{T W}$} & \multicolumn{5}{|c|}{ Standard Deviation $\ln c^{T} / c^{T W}$} \\
\hline & \multicolumn{5}{|c|}{ horizon(years) } & \multicolumn{5}{|c|}{ horizon(years) } & \multicolumn{5}{|c|}{ horizon(years) } \\
\hline & 1 & 10 & 30 & 50 & 100 & 1 & 10 & 30 & 50 & 100 & 1 & 10 & 30 & 50 & 100 \\
\hline process 1 & .017 & .028 & .029 & .029 & .028 & .082 & .014 & .014 & .015 & .014 & .015 & .025 & .025 & .025 & .025 \\
\hline process 2 & .020 & .063 & .107 & .139 & .195 & .012 & .034 & .060 & .077 & .106 & .017 & .052 & .089 & .116 & .164 \\
\hline process 3 & .018 & .085 & .151 & .197 & .278 & .009 & .044 & .076 & .099 & .136 & .016 & .073 & .130 & .171 & .243 \\
\hline process 4 & .018 & .086 & .152 & .198 & .279 & .009 & .044 & .077 & .100 & .137 & .016 & .074 & .131 & .172 & .243 \\
\hline \multirow[t]{4}{*}{ process 5} & .017 & .061 & .089 & .110 & .147 & .009 & .045 & .079 & .102 & .145 & .015 & .041 & .04 & .04 & .041 \\
\hline & \multicolumn{5}{|c|}{ Standard Deviation $\ln c^{N}$} & \multicolumn{5}{|c|}{ Standard Deviation $\ln c^{N W}$} & \multicolumn{5}{|c|}{ Standard Deviation $\ln c^{N} / c^{N W}$} \\
\hline & \multicolumn{5}{|c|}{ horizon(years) } & \multicolumn{5}{|c|}{ horizon(years) } & \multicolumn{5}{|c|}{ horizon(years) } \\
\hline & 1 & 10 & 30 & 50 & 100 & 1 & 10 & 30 & 50 & 100 & 1 & 10 & 30 & 50 & 100 \\
\hline process 1 & .017 & .026 & .026 & .026 & .025 & .010 & .016 & .017 & .016 & .016 & .013 & .020 & .020 & .020 & .020 \\
\hline process 2 & .020 & .064 & .109 & .140 & .196 & .013 & .043 & .072 & .090 & .125 & .016 & .048 & .082 & .107 & .151 \\
\hline process 3 & .019 & .077 & .135 & .174 & .245 & .011 & .045 & .083 & .106 & .147 & .015 & .060 & .106 & .139 & .200 \\
\hline process 4 & .019 & .074 & .131 & .175 & .260 & .011 & .046 & .077 & .098 & .136 & .015 & .058 & .106 & .145 & .222 \\
\hline \multirow[t]{4}{*}{ process 5} & .019 & .063 & .094 & .114 & .153 & .011 & .049 & .083 & .105 & .146 & .015 & .041 & .044 & .044 & .044 \\
\hline & \multicolumn{5}{|c|}{$\operatorname{corr}\left(\ln c^{N}, \ln c^{T}\right)$} & \multicolumn{5}{|c|}{$\operatorname{corr}\left(\ln c^{N W}, \ln c^{T W}\right)$} & \multicolumn{5}{|c|}{$\operatorname{corr}\left(\ln c^{N} / c^{N W}, \ln c^{T} / c^{T W}\right)$} \\
\hline & \multicolumn{5}{|c|}{ horizon(years) } & \multicolumn{5}{|c|}{ horizon(years) } & \multicolumn{5}{|c|}{ horizon(years) } \\
\hline & 1 & 10 & 30 & 50 & 100 & 1 & 10 & 30 & 50 & 100 & 1 & 10 & 30 & 50 & 100 \\
\hline process 1 & 0.65 & 0.66 & 0.65 & 0.65 & 0.64 & 0.90 & 0.91 & 0.90 & 0.90 & 0.89 & 0.56 & 0.55 & 0.55 & 0.55 & 0.55 \\
\hline process 2 & 0.69 & 0.70 & 0.69 & 0.69 & 0.69 & 0.91 & 0.92 & 0.91 & 0.91 & 0.91 & 0.57 & 0.57 & 0.57 & 0.58 & 0.59 \\
\hline process 3 & 0.67 & 0.68 & 0.68 & 0.68 & 0.68 & 0.88 & 0.90 & 0.89 & 0.88 & 0.88 & 0.59 & 0.59 & 0.59 & 0.60 & 0.61 \\
\hline process 4 & 0.68 & 0.77 & 0.88 & 0.93 & 0.96 & 0.86 & 0.91 & 0.94 & 0.96 & 0.98 & 0.61 & 0.72 & 0.86 & 0.91 & 0.96 \\
\hline process 5 & 0.67 & 0.75 & 0.81 & 0.83 & 0.84 & 0.87 & 0.89 & 0.87 & 0.87 & 0.86 & 0.58 & 0.58 & 0.56 & 0.56 & 0.56 \\
\hline
\end{tabular}

Table 2: Moments Generated by the Estimated Processes

Notes : The table reports several moments associated with the log of tradables and non-tradables consumption (and their global counterparts), at various horizons, based on 1000 simulations of the 5 processes estimated in Table 1. The processes are: (1) stationary process, (2) random walk process (3) AR process in growth rates, (4) non-stationary process with sectoral cointegration, and (5) non-stationary process with global cointegration. 


\begin{tabular}{|lcc|}
\hline \hline lag augmentation & 2 & 3 \\
\hline Variable & & \\
$\ln c^{N}$ & -1.44 & 0.19 \\
$\ln c^{T}$ & -2.98 & -1.62 \\
$\ln c^{N}-\ln c^{N W}$ & 0.05 & 1.45 \\
$\ln c^{T}-\ln c^{T W}$ & -2.39 & -2.19 \\
$\ln c^{N}-\ln c^{T}$ & 1.19 & 0.74 \\
\hline
\end{tabular}

Table 3: Unit Root Test Statistics

Notes : The table reports the unit root test statistic developed by Im, Peseran and Shin (1995). Under the null of a unit root the statistic has a standard normal distribution. The statistic is a function of the average across countries of the augmented Dickey-Fuller t-statistic. Results are shown for both two and three augmentation lags. 


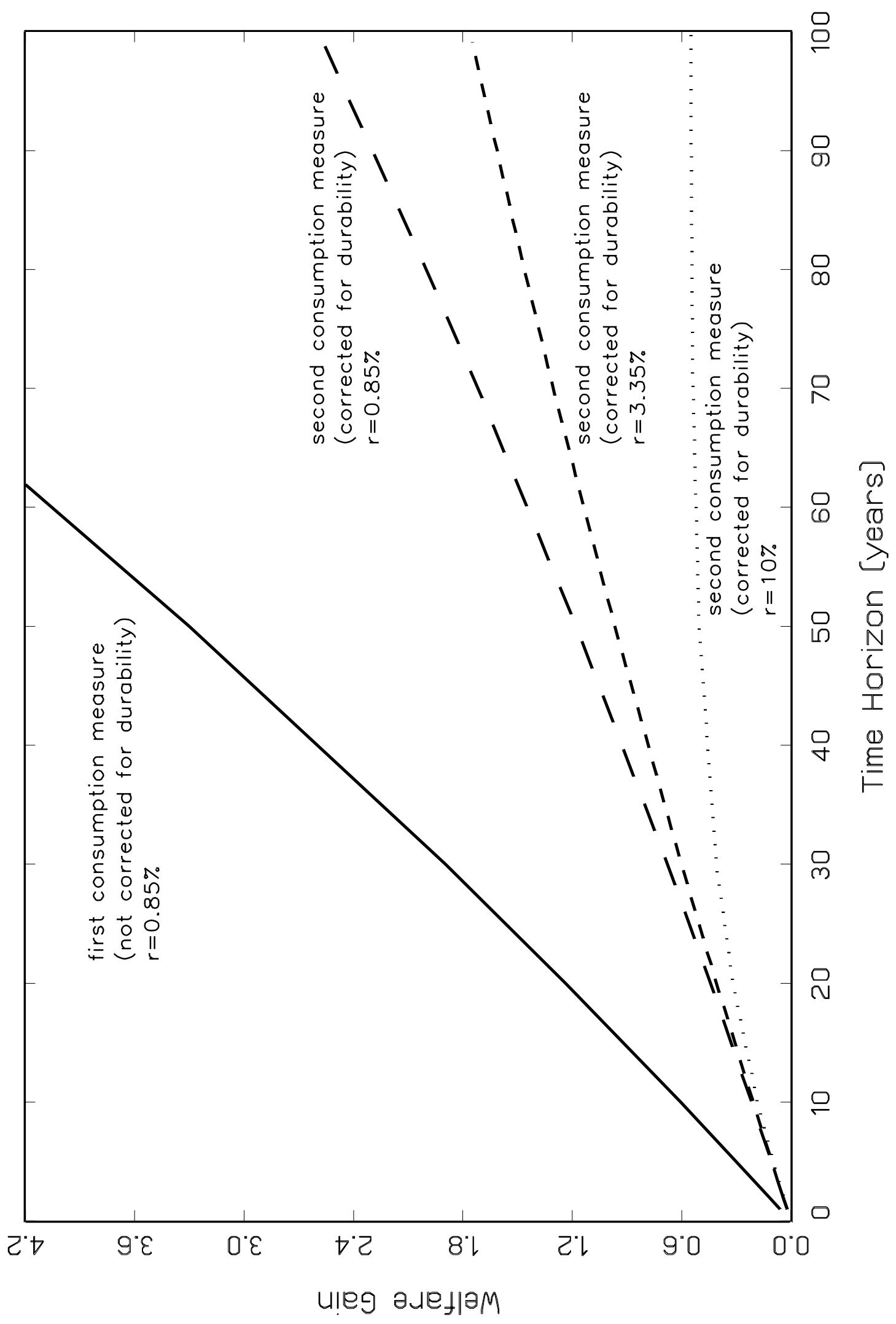




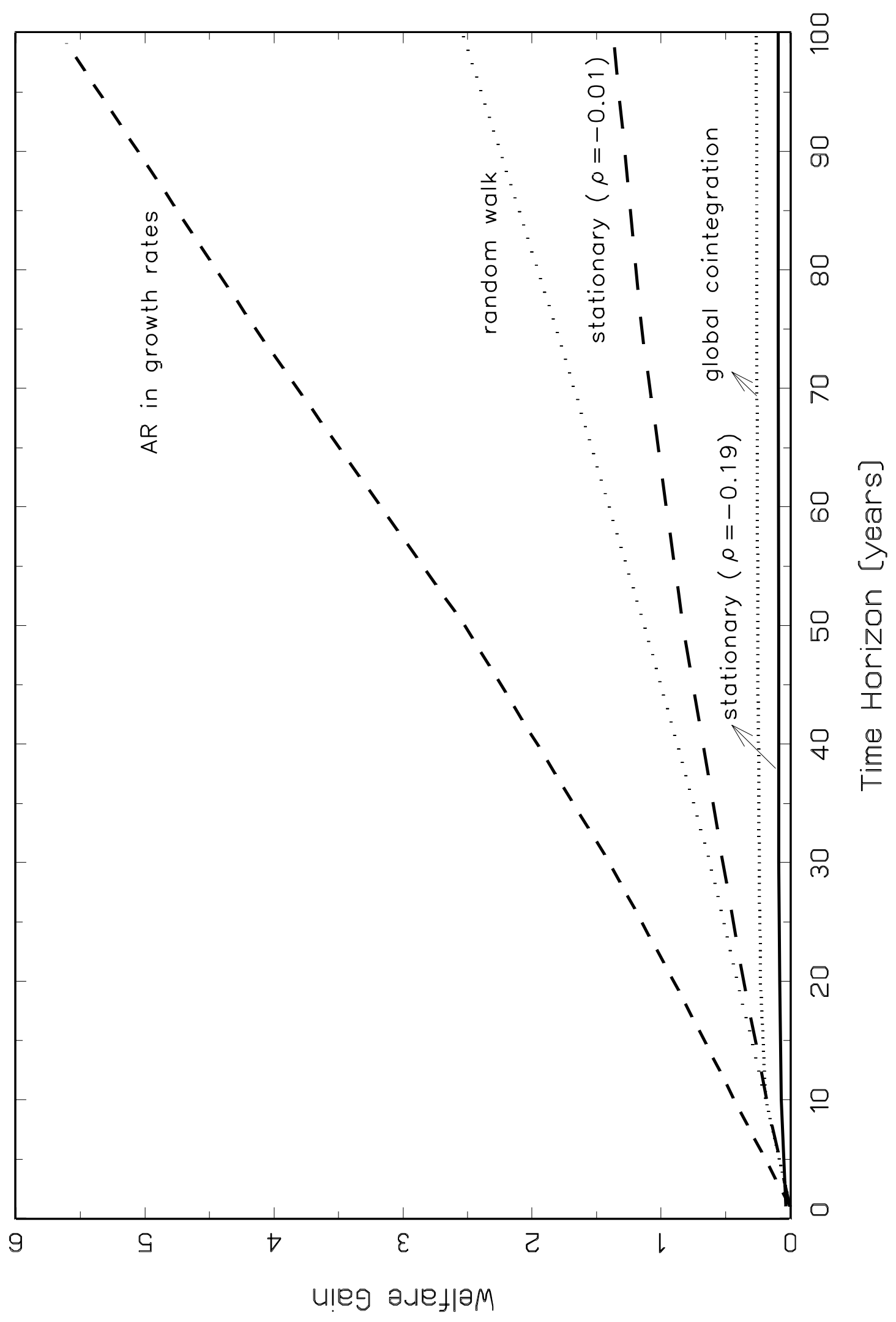




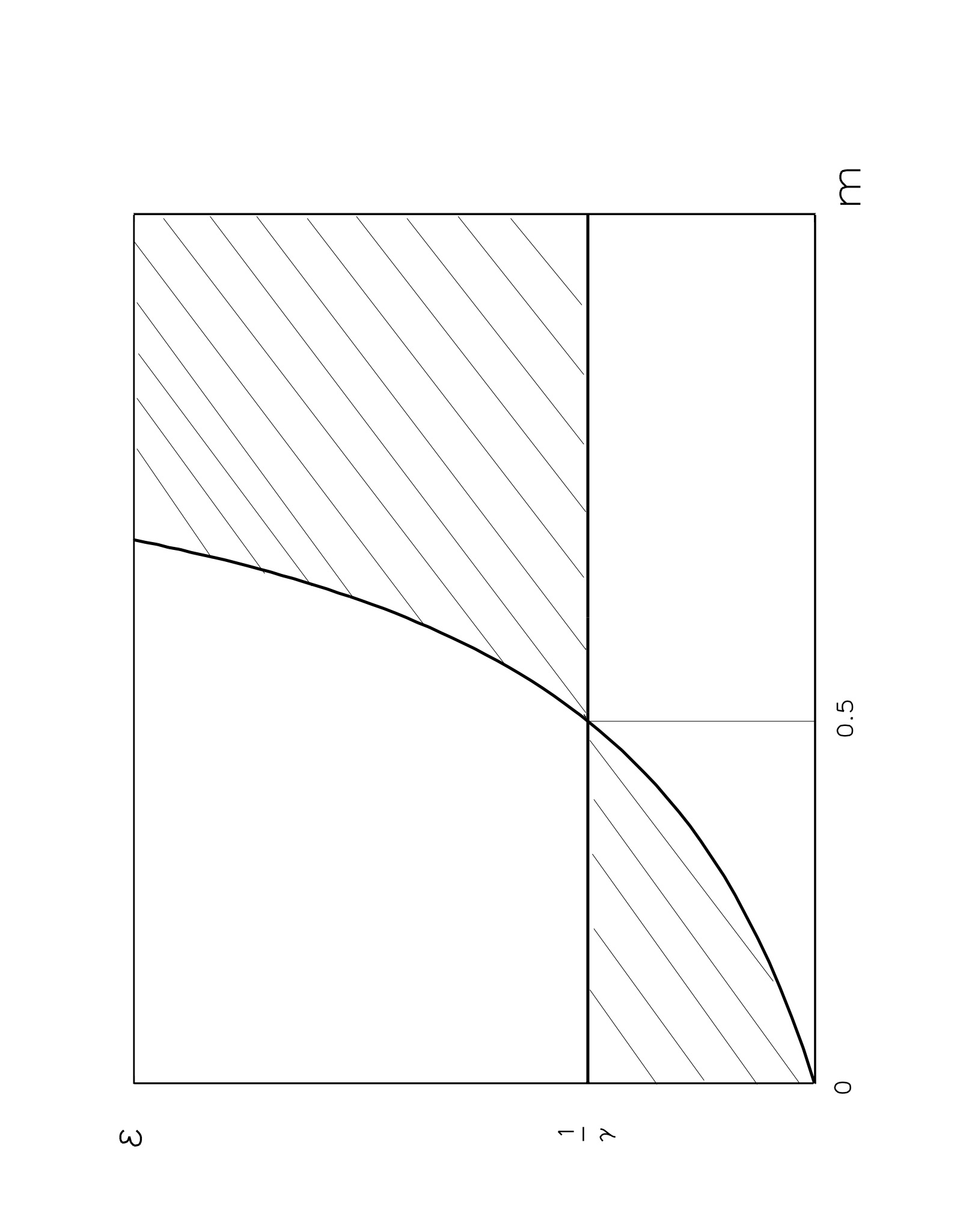



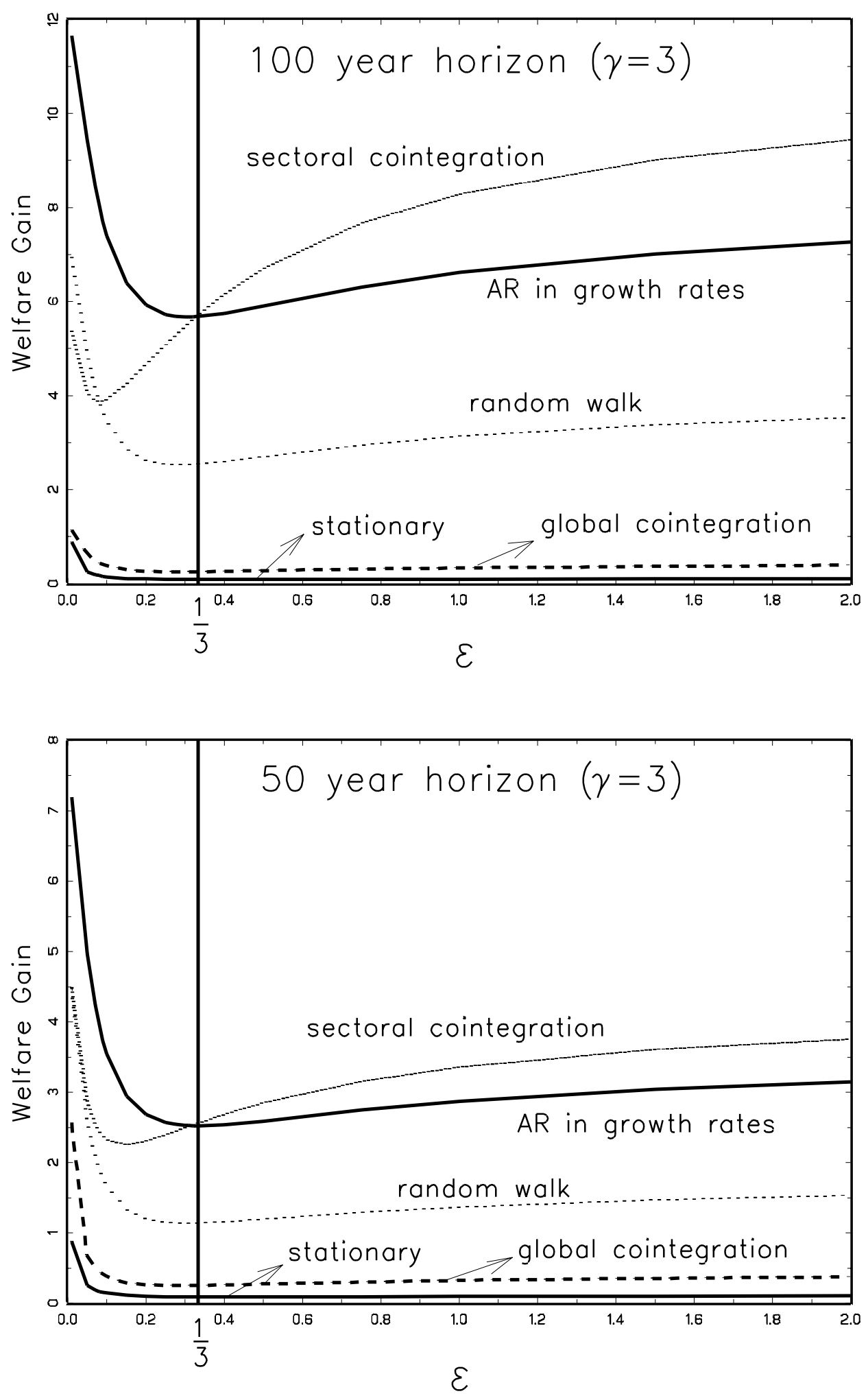